\title{
Tierras de común repartimiento y formación de ranchos en el sistema de riego de Cuautitlán, Estado de México, 1856-1911
}

Lands of common distribution and formation of ranches in the irrigation system of Cuautitlán, State of Mexico,
1856-1911

Porfirio Neri Guareros

Centro de Investigaciones en Ciencias Sociales y Humanidades, Universidad Autónoma del Estado de México, México

ce_nery@yahoo.com.mx

\section{Gloria Camacho Pichardo}

Centro de Investigaciones en Ciencias Sociales y Humanidades, Universidad Autónoma del Estado de México, México

glocapi@yahoo.com.mx

\section{ResUMen:}

En México la ley de desamortización de 25 de junio de 1856 estableció que todas las fincas rústicas y urbanas en propiedad de las corporaciones civiles o eclesiásticas debían adjudicarse en propiedad individual. La mayoría de los pueblos indígenas se resistieron a desamortizar sus tierras comunales, pero algunos vecinos aceptaron rápidamente la desamortización de sus tierras de común repartimiento; por ejemplo, los vecinos de varias municipalidades que integraban el sistema de riego de Cuautitlán. En este sentido, el objetivo de este artículo es analizar el proceso desamortizador de las tierras de común repartimiento y la formación de ranchos en la municipalidad de Cuautitlán, entre 1856 y 1911 . Se establece que el traslado de las tierras de común repartimiento a propiedad individual se dio rápidamente debido a tres aspectos: la posesión individual de las tierras, la pérdida del sentido comunitario sobre las mismas y la existencia del recurso hídrico. Así mismo, se concluye que los rancheros lograron acumular tierras desamortizadas, porque la venta de tierras era una práctica habitual en la región. Además, los nuevos propietarios vieron en las tierras y el recurso hídrico oportunidades de desarrollo económico enfocado a la actividad ganadera y lechera. Finalmente, el texto hace evidente que las formas de acceder y disfrutar de las tierras de común repartimiento sufrióeron cambios durante el siglo XIX; por lo que no podemos continuar considerándolas como tierras individuales que eran distribuidas entre las familias para su sobrevivencia.

Palabras clave: Derechos de propiedad, Desamortización, Mercado de tierras, Ranchos, Historia agrario.

\section{ABstract:}

In Mexico, the desamortización law of June 25, 1856 established that all rustic and urban farms owned by civil or ecclesiastical corporations should be awarded individually. Most of the indigenous peoples resisted to confiscate their communal lands, but some neighbors quickly accepted the desamortización of their lands of común repartimiento; for example, the neighbors of several municipalities that integrated the irrigation system of Cuautitlán. In this sense, the objective of this article is to analyze the desamortización process of the lands of común repartimiento and the formation of ranches in the municipality of Cuautitlán, between 1856 and 1911. It is established that the transfer of the lands of común repartimiento to individual property It happened quickly due to three aspects: the individual possession of the lands, the loss of community sense of them and the existence of the water resource. Likewise, it is concluded that the ranchers managed to accumulate desamortizadas lands, because the sale of land was a common practice in the region. In addition, the new owners saw economic development opportunities in the land and water resources focused on livestock and dairy activities. Finally, the text makes it clear that the ways of accessing and enjoying the lands of común repartimiento underwent changes during the 19th century; so we cannot consider them yet as individual lands that were distributed among the families for their survival.

KEYWORDS: Property rights, Desamortización, Land market, Ranches, Agricultural history. 


\section{INTRODUCCIÓN}

En México la ley del 25 de junio de 1856, también llamada “Ley Lerdo", estableció la desamortización de fincas rústicas y urbanas, que tenían en propiedad las corporaciones civiles y eclesiásticas. En este sentido, la iglesia, los ayuntamientos, pueblos, cofradías y en general toda fundación que tuviera el carácter de duración perpetua e indefinida debía adjudicar sus tierras en propiedad individual (Labastida, 1893, pp. 3, 5).

En el Estado de México, como en las demás entidades federativas, muchos pueblos lograron conservar sus distintos tipos de tierras a través de varios mecanismos como la rebelión o la desobediencia civil; así como a través de la promoción de juicios y la formación de sociedades agrícolas (Camacho, 2015; Neri, 2011). No obstante, también hubo pueblos que aceptaron rápidamente la desamortización de sus tierras de común repartimiento, como sucedió en la municipalidad de Cuautitlán. Las tierras de esta municipalidad presentaban una característica importante, como era el estar ubicadas dentro del sistema de riego de la Pila Real de Atlamica; ${ }^{1}$ lo cual, entre otros aspectos, posibilitó que las tierras desamortizadas fueran acaparadas por un pequeño grupo de rancheros.

En esta perspectiva, el objetivo de este artículo es analizar la adjudicación de tierras de común repartimiento y la formación de ranchos en el sistema de riego de la Pila Real de Atlamica, entre 1856 y 1911 . El texto tiene dos ejes analíticos: en primer lugar, el cambio de propiedad comunal a propiedad individual, enfocándonos exclusivamente en las tierras de común repartimiento; en segundo lugar, la conformación de ranchos a partir de la compraventa de tierras desamortizadas. Este trabajo plantea que la posesión individual de las tierras, aunado a la existencia del recurso hídrico, propició una rápida desamortización y el surgimiento de los ranchos en el sistema de riego.

A lo largo del texto emplearemos el concepto de propiedad. Joaquín Escriche consideraba que la propiedad o dominio era: "el derecho de gozar y disponer libremente de nuestras cosas, en cuanto las [sic] leyes no se opongan" (Escriche, 1851, pp. 1392; 567-568). De acuerdo a lo anterior, la propiedad implicaba: el derecho que tenían los individuos a gozar y disponer libremente de un bien, con independencia de terceros; siempre y cuando las leyes no se opusieran o se perjudicasen los derechos de un tercero. Durante el siglo XIX, para referirse a este tipo de propiedad se empleaban las palabras propiedad individual, propiedad particular, pleno dominio o simplemente propiedad; por ello en el texto, con el fin de no caer en confusiones y anacronismos, nos referiremos a dicha propiedad como propiedad individual.

La historiografía sobre el proceso desamortizador versa sobre distintas temáticas: tipo de bienes de los pueblos, adjudicaciones de tierras comunales, resistencia de los pueblos, adaptación de los pueblos, juicios o problemas por tierras, entre otras. Las tierras de común repartimiento han recibido atención puntual por parte de algunos investigadores. A los trabajos de Margarita Menegus (1995, 1999, 2001) sobre las tierras de común repartimiento en el Estado de México, se puede agregar el de Trinidad Quezada y el de María Antonieta Pacheco. El primer autor afirma que la ley de desamortización provocó una amplia "privatización" de tierras comunales pertenecientes a las corporaciones civiles en la municipalidad de Metepec a partir de 1867; no obstante, la mayoría de las tierras de común repartimiento adjudicadas en propiedad individual continuaron en poder de los vecinos de los pueblos (Quezada, 1996). La segunda autora manifiesta que los vecinos de Tepotzotlán se resistieron a la desamortización porque consideraban las tierras de común repartimiento como suyas, ya que cada familia las había tenido por generaciones (Pacheco, 2011, p. 21).

El trabajo que se acerca más al tema es el de Édgar Mendoza, el cual aborda las tierras de común repartimiento en la municipalidad de San Juan Teotihuacán. El autor encuentra que los vecinos acudieron rápidamente a desamortizar sus tierras y que a pesar de ser adjudicadas en propiedad "privada" continuaron llamándose "de común repartimiento". En este sentido, el término se continuó utilizando para referirse a aquellas tierras que fueron adjudicadas y que tenían el fin de cobrar un censo redimible a favor de las arcas municipales (Mendoza, 2017, p. 1968). 
En lo que respecta al tema del mercado de tierras poco o nada se ha escrito al respecto. Juventino García establece que en Atzalan, Veracruz, la compraventa de tierras inició en la década de 1860 como consecuencia de la desamortización y permitió a las élites afianzar el proceso de acaparamiento de la propiedad raíz (García, 2007, pp. 183, 187). Édgar Mendoza manifiesta que en Cuicatlán, Oaxaca, gran parte de la desamortización se dio entre 1889 y 1900, principalmente en aquellas tierras adecuadas para la agricultura comercial; siendo las tierras aptas para el cultivo de café las más codiciadas por los compradores. El autor manifiesta que la economía porfirista, la llegada del ferrocarril en 1892 y la presión de las leyes, generaron un mercado cada vez más cotizado de tierras. Este último fue aprovechado en la primera mitad de la década de 1890 por la élite local y por inversionistas nacionales y extranjeros para comprar las tierras (Mendoza, 2007, pp. 111-115).

En la municipalidad de Cuautitlán, y en general en el valle de Cuautitlán, el mercado de tierras no puede atribuirse a la expedición de la ley del 25 de junio de 1856, puesto que antes de esta ley ya había un mercado de tierras. La legislación, más bien, posibilitó que algunos rancheros y hacendados entraran al mercado de tierras, logrando con ello acumular considerables extensiones de tierra. En la municipalidad de Cuautitlán a partir de 1857 la enajenación de tierras de común repartimiento fue aumentando considerablemente, alcanzando su máximo desarrollo en la década de 1880 .

\section{La Pila Real de Atlamica: Distribución y administración del agua}

Los pueblos que examinaremos se ubican en el valle de Cuautitlán, localizado al norte del Estado de México. El clima de la región es templado y el suelo mayoritariamente fértil. La planicie tiene una altitud que oscila entre los 2200 y los 2,300 msnm y está rodeada por altas montañas: al norte por las estribaciones de la Sierra de Tenzontlalpan y Pachuca (Orozco, 1864, pp. 109-110); al sur por la Sierra de Guadalupe, al este por las estribaciones de la Sierra Nevada y al oeste por la Sierra de Tepotzotlán y la Sierra de las Cruces (Sandre, 2012, p. 124; Orozco, 1864, p. 118). La altura de estas montañas fluctúa entre los 2800 y 3800 msnm. ${ }^{2}$

Las ricas y extensas coberturas forestales, en lo alto de la Sierra de las Cruces, proveían de vastos manantiales y escurrimientos naturales a la región (Venegas, 1923). Uno de estos escurrimientos era el río Cuautitlán, el cual recogía la mayor parte de las aguas de la serranía ${ }^{3}$ para después dirigirse al noreste por las montañas y las tierras del distrito de Tlalnepantla y Cuautitlán; al llegar a la planicie del valle parte de sus aguas eran derivadas a la Pila Real de Atlamica para fertilizar las tierras de las haciendas, los ranchos y los pueblos. ${ }^{4}$ El río continuaba su curso hacia Teoloyucan donde recibía las aguas del río Tepotzotlán, para finalmente dirigirse hacia el tajo de Nochistongo y el río Tula (Morlán, 2012, pp. 24-26).

El repartidor general de aguas del río Cuautitlán conocido como "Pila Real de Atlamica" (véanse figuras 1 y 2) se construyó a finales del siglo XV, con el fin de distribuir el agua entre los pueblos del valle para usos agrícolas y domésticos (Sandre, 2007, p. 37). ${ }^{5}$ Consumada la conquista, la Corona española se convirtió en la propietaria de las tierras y las aguas de los territorios conquistados. Con esta atribución la Corona otorgó su uso a españoles e indígenas mediante mercedes reales o repartimiento, documentos que fungieron como títulos de posesión de aguas. 
Figura 1. Valle de Cuautitlán

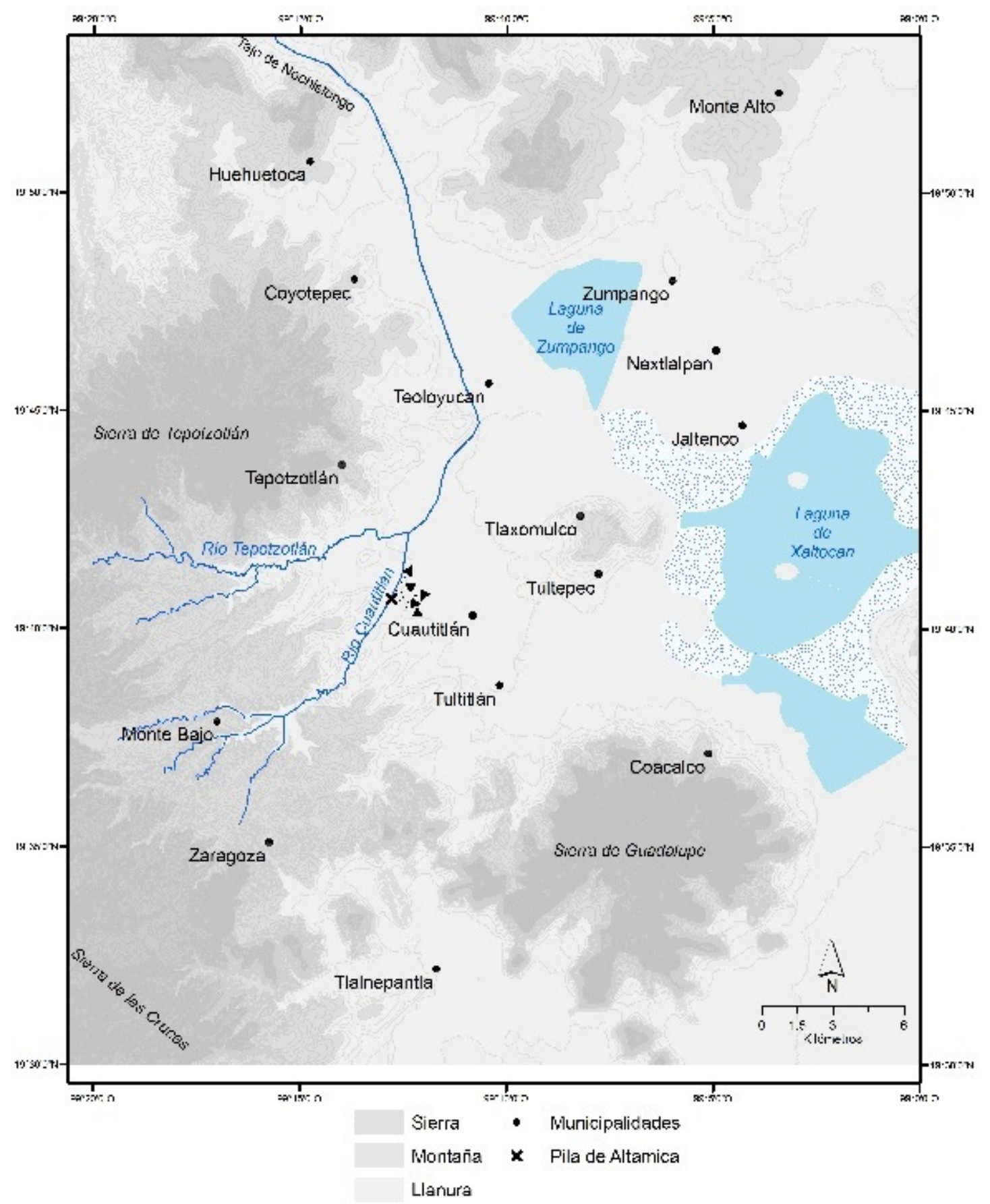

Fuente: Elaboración propia con base en documentación de archivo.

A partir del siglo XVIII, los conflictos por el uso y control del agua aumentaron de manera considerable, debido a la explotación intensiva de la agricultura y la ganadería (Sandre, 2007, p. 37). Los usos del agua en el valle de Cuautitlán no fueron ajenos a esta situación, ya que desde 1679 se ventilaron varios litigios ante la Real Audiencia. ${ }^{6}$ Por ejemplo, en 1762 como resultado de las diferencias y el aumento de los usuarios se dio un repartimiento de aguas del río Cuautitlán a través de la Pila Real de Atlamica (Sandre, 2007, p. 39). ${ }^{7}$ 
Tabla 1. Repartimiento de las aguas del río Cuautitlán en 1762

\begin{tabular}{|c|c|c|}
\hline Acequia & Usuarios & Cantidad \\
\hline \multirow{2}{*}{$\begin{array}{l}\text { Santa Bárbara (canal de } \\
\text { San Lorenzo) }\end{array}$} & Pueblo de Santa Bárbara & 16 surcos \\
\hline & Hacienda de Tecoac & 2 surcos \\
\hline \multirow{4}{*}{ Guayapango } & Hacienda de Tecoac & 3 surcos \\
\hline & Hacienda de Sabino & 4 surcos \\
\hline & Hacienda de San Mateo Atocan & 10 surcos \\
\hline & Pueblos de San Mateo y San Sebastián Xala & 8 surcos \\
\hline \multirow{8}{*}{ Córdova } & Pueblo de Cuautitlán y Hacienda del Sabino & 4 surcos \\
\hline & Hacienda de Coamatla & $11 / 2$ surcos \\
\hline & Rancho de Angulo & 1 surco \\
\hline & Hacienda la Corregidora & 14 surcos \\
\hline & Rancho Cadena & $22 / 3$ surcos \\
\hline & Pueblos de San Miguel y Visitación & 2 surcos \\
\hline & Pueblo de Tultepec & 2 surcos \\
\hline & Hacienda de Xaltipac & 10 surcos \\
\hline \multirow{6}{*}{$\begin{array}{l}\text { De Cuautitlán (río } \\
\text { Chiquito) }\end{array}$} & Hacienda de Coamatla & $1 \frac{1}{2}$ surcos \\
\hline & Rancho de Angulo & $1 / 2$ surco \\
\hline & Pueblo de Cuautitlán y barrio de Tlaltempan & 2 surcos \\
\hline & Rancho de Rivero & 1 surco \\
\hline & Hacienda de Atempan & 6 surcos \\
\hline & Barrio de Santa María Axomulco & 1 surco \\
\hline \multirow{11}{*}{ Molino } & Hacienda de Coamatla & 1 surco \\
\hline & Rancho perteneciente a Joseph Flores & 1 surco \\
\hline & Espíndola & 1 surco \\
\hline & Caseríos de la cabecera de Cuautitlán & $21 / 2$ surcos \\
\hline & Rancho perteneciente a Manuel Alvares & $1 \frac{1}{2}$ surcos \\
\hline & Molino & 22 surcos \\
\hline & Pueblo de Tultitlán & 14 surcos \\
\hline & Rancho del Salitre & 1 surco \\
\hline & Barrio de San Joseph & 2 surcos \\
\hline & Hacienda de Cartagena & $22 / 3$ surcos \\
\hline & Hacienda los Portales & $22 / 3$ surcos \\
\hline
\end{tabular}

Fuente: Sandre (2007).

En el documento de reparto se estableció la derivación de 120 surcos de agua del río Cuautitlán hacía la Pila Real de Atlamica, que a su vez se distribuían mediante cinco acequias para regar las tierras de los pueblos, ranchos y haciendas. El documento también estableció la derivación de 15 surcos de agua del río Cuautitlán, a través de una cuneta, para regar tierras ubicadas en el pueblo de Teoloyucan. El aforo total de agua era de 2.710 litros por segundo, correspondiéndole a cada surco 20 litros por segundo. 
Figura 2. Pila Real de Atlamica y canales de distribución

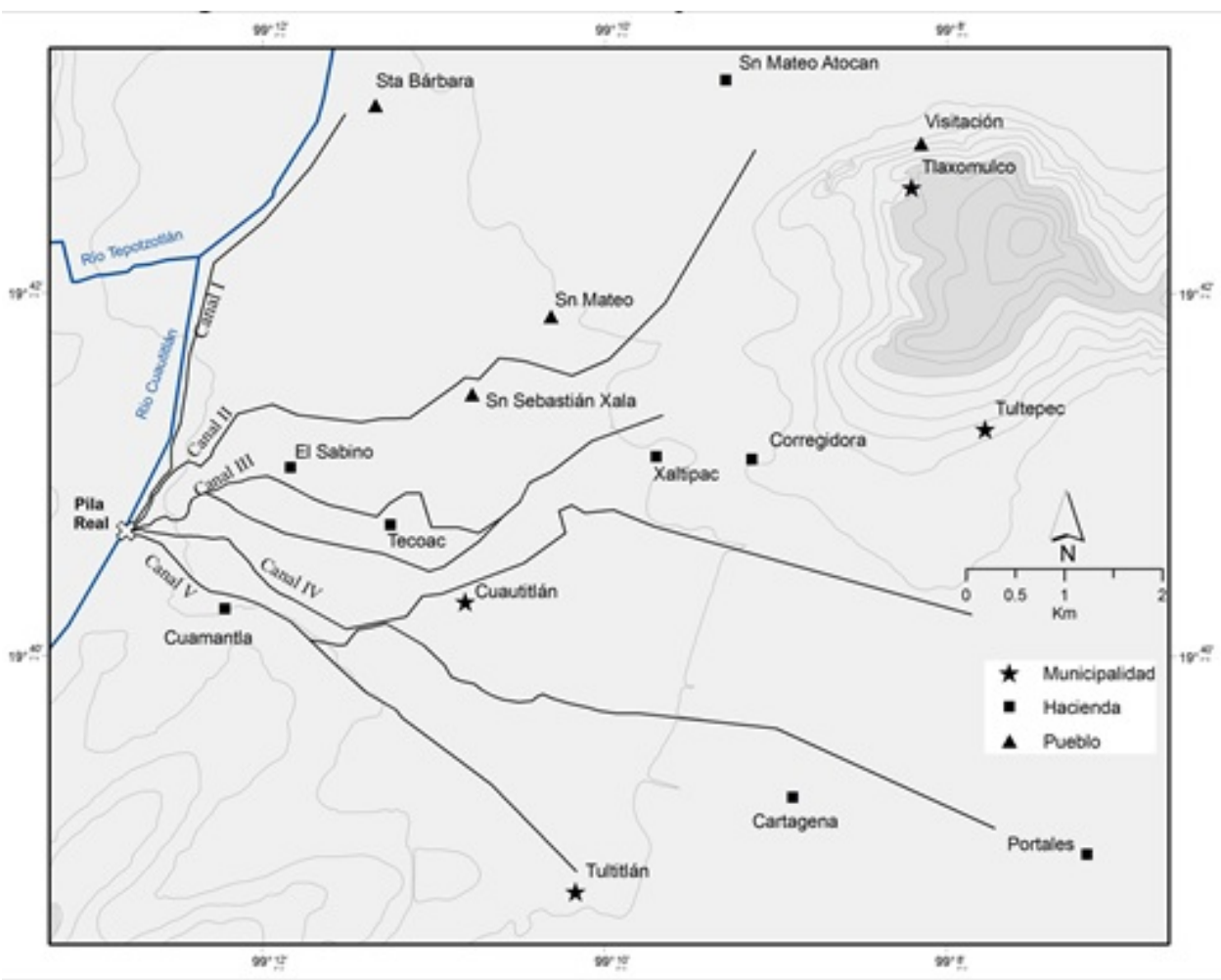

Fuente: Elaboración propia con base en documentación de archivo.

A decir de Yolanda Reséndiz la distribución del agua se realizó conforme a los volúmenes de agua asignados en las mercedes que cada usuario presentó; pero Israel Sandre considera más probable que el reparto haya estado determinado por la cantidad de tierra agrícola que tenía cada uno de los usuarios (Sandre, 2007, p. 40). Concordamos con la segunda postura, ya que a los que tenían más tierras se les dio más agua; por ejemplo, a cinco haciendas se les dio 45 surcos de agua de los 120 que ingresaban a la Pila Real.

En general, las haciendas y los ranchos obtuvieron en el reparto el $57.5 \%$ del agua y los pueblos el 42.5 $\%$. Así, se podría decir que la distribución fue equitativa; pero si vemos la distribución del agua por acequia, notamos que el reparto fue bastante desigual como se puede ver en la siguiente tabla.

Tabla 2. Distribución del agua por acequia

\begin{tabular}{|l|c|c|}
\hline \multicolumn{1}{|c|}{ Acequia } & \multicolumn{1}{|c|}{$\begin{array}{c}\text { Haciendas y } \\
\text { ranchos } \\
\%\end{array}$} & $\begin{array}{c}\text { Pueblos } \\
\%\end{array}$ \\
\hline 1. Santa Bárbara & 11 & 89 \\
\hline 2. Guayapango & 68 & 32 \\
\hline 3. Córdova & 84 & 16 \\
\hline 4. Cuautitlán & 75 & 25 \\
\hline 5. Molino & 36 & 64 \\
\hline
\end{tabular}

Por una parte, las haciendas y los ranchos ubicados en las acequias de Guayapango, Córdova y Cuautitlán obtuvieron mayores volúmenes de agua (véanse tabla 1 y 2); ello hace pensar que en esta parte del sistema de riego las haciendas habían acaparado parte de las tierras de los pueblos. Por otra parte, los pueblos que mejor resultaron beneficiados en el reparto fueron los de Teoloyucan, Santa Bárbara, San Mateo, San Sebastián 
Xala, San Lorenzo y Santa María Huacatitla. El primer pueblo recibió 15 surcos de agua a través de la cuneta de "Teoloyucan", en tanto que los pueblos restantes recibieron 16 surcos de agua a través del primer canal llamado "Santa Bárbara”. Los pueblos de San Mateo y San Sebastián Xala recibieron ocho surcos más a través del segundo canal nombrado "Guayapango" (véanse tabla 1 y 2). El hecho de que los pueblos ubicados en las acequias de Santa Bárbara y Guayapango hayan recibido más agua implica que las tierras de común repartimiento aún estaban en su poder, pero este panorama cambió con la expedición de la ley del 25 de junio de 1856.

Margadant (1989) consideró que los derechos por el agua provenientes de los repartos no eran permanentes, ya que siempre estaba latente la posibilidad de nuevos conflictos y de realizar una nueva distribución. Para él la "propiedad absoluta" sobre el agua durante la Colonia no existía, pues sólo se trataba de derechos de uso que podían ser modificados ante nuevos conflictos. En este sentido, los usufructuarios tenían más bien el "dominio útil o directo", que consistía en el derecho de usar o de poseer (pp. 140, 142-143). Si bien no podemos decir que había propiedad absoluta, si podemos mencionar que, en algunos casos, los pueblos y las haciendas tenían derechos exclusivos sobre el agua como el de rentarla, venderla y excluir a otros del acceso a ella. ${ }^{8}$

Al terminar el periodo colonial el control y dominio del agua quedó en manos de los pueblos y haciendas. En el valle de Cuautitlán estos actores mantuvieron la propiedad sobre el agua del río Cuautitlán que entraba a la Pila Real de Atlamica. Los ayuntamientos, principalmente el de Cuautitlán, eran los encargados de administrar el recurso hídrico; teniendo injerencia directa en el otorgamiento de derechos, la resolución de conflictos, las reglamentaciones, el control de los procesos de distribución del líquido, el nombramiento de aguador y la organización de las obras de construcción y conservación de las presas y canales (Sandre, 2007, p. 42). El regidor de aguas de la municipalidad de Cuautitlán nombraba a los jueces de aguas, que se encargaban de repartir el líquido de acuerdo con las peticiones. Cuando uno de los interesados requería agua para regar sus terrenos, acudía al regidor y este le otorgaba el permiso y avisaba al juez correspondiente para que lo pusiera en posesión del líquido por el tiempo y la cantidad convenidos. ${ }^{9}$

Por lo regular se considera que los pueblos disfrutaban de las aguas bajo el régimen de propiedad comunal; pero hemos de decir que definir el régimen de propiedad de las aguas en un sistema de riego como el de la Pila Real de Atlamica resulta complicado. Primero, porque los usufructuarios del agua sustentaron su propiedad conforme al reparto de 1762 que les daba el uso exclusivo de cierta cantidad de agua; segundo, porque los usufructuarios eran pueblos, haciendas y posteriormente ranchos; tercero, porque varios ayuntamientos tenían injerencia administrativa en una parte del sistema de riego; cuarto, porque los usufructuarios se consideraban propietarios de las aguas del río con independencia de terceros; quinto, porque no todos los vecinos tenían derecho al agua de la Pila Real.

No pretendemos establecer cuál era el régimen de propiedad de las aguas, pues lo que nos interesa es mostrar cómo estaba constituido el sistema de riego de la Pila Real para entender cómo el recurso hídrico determinó la desamortización de tierras y el acaparamiento de las mismas por los rancheros. No obstante, hemos de decir que para la segunda mitad del siglo XIX los pueblos consideraban el agua como propiedad comunal y los hacendados como propiedad individual; en tanto que los rancheros que compraron tierras desamortizadas y no estaban incluidos en el reparto de 1762 disfrutaron del agua mediante servidumbres.

La forma y los tiempos de distribución del agua fueron cambiando durante el siglo XIX, sobre todo con el proceso desamortizador, pues ello originó la aparición de nuevos usufructuarios como los rancheros, quienes reclamaron el derecho a usar el líquido para regar sus tierras. A finales de dicho siglo la forma de distribuir el agua de la Pila Real de Atlamica se realizaba por días; por ejemplo, el pueblo de Santa Bárbara disfrutaba del agua durante seis días consecutivos. El aumento de usuarios, aunado a que las obras hidráulicas no recibían el mantenimiento adecuado, propició la disminución del recurso hídrico. ${ }^{10}$

Aboites (1998) considera que fue a partir de la "Ley sobre vías generales de comunicación" del 5 de junio de 1888 cuando el gobierno federal empezó a ganar participación sobre los recursos hídricos del país. Mediante 
dicha ley el gobierno federal obtuvo facultades de vigilancia, policía y reglamentación sobre las aguas de los mares territoriales, esteros y lagunas, lagos y ríos navegables, lagos y ríos que servían de límites entre países y entidades federativas, y los canales construidos con fondos gubernamentales (Aboites, 1998, pp.13-14, 27, 30).

Las posteriores leyes sobre aguas permitieron al gobierno federal ejercer un control más estricto sobre el uso de los recursos hídricos. La ley federal del 6 de junio de 1894 autorizó al gobierno a otorgar concesiones de agua para uso de riego e industrial; la "Ley de clasificación y régimen de los bienes inmuebles federales del 18 de diciembre de 1902" incluyó las aguas como bienes de dominio público federal; y la "Ley sobre aprovechamiento de aguas de jurisdicción federal, del 13 de diciembre de 1910" confirmó el principio de la jurisdicción federal sobre las aguas nacionales que se entendían bajo el dominio público de la federación (Aboites, 1998, p. 88). No obstante, la injerencia del gobierno federal fue lenta, lo cual permitió que algunos pueblos y haciendas continuaran ejerciendo derechos de propiedad sobre el recurso hídrico. Ese fue el caso de los pueblos y haciendas de Cuautitlán, que mantuvieron el control sobre la distribución de las aguas de la Pila Real de Atlamica hasta principios del siglo XX.

Durante nuestro periodo de estudio la propiedad y administración de las aguas estuvo en manos de los pueblos que disfrutaban de las aguas de la Pila Real. No obstante, a finales del siglo XIX y principios del $\mathrm{XX}$ algunos usufructuarios de la Pila real empezaron a pedir confirmación de derechos sobre el agua y a solicitar concesiones ante la Secretaría de Fomento para regar sus terrenos. En 1896 María Dolores Moncada, propietaria de la hacienda de Cartagena y del Rancho de la Cadena, solicitó la confirmación de derechos sobre las aguas del río Cuautitlán que empleaba en el riego de sus tierras. ${ }^{11}$ Los vecinos de Coyotepec en $1903^{12}$ y los vecinos de Teoloyucan en 1910 solicitaron una concesión de aguas del río Cuautitlán a la Secretaria de Fomento para regar sus terrenos. ${ }^{13}$

\section{DESAMORTIZACIÓN DE LAS TIERRAS DE COMÚN REPARTIMIENTO}

En México los pueblos indígenas desde la independencia hasta 1856 mantuvieron personalidad y representación jurídica; es decir, podían tener en propiedad comunal bienes raíces. Si bien todas las tierras eran comunales, al interior de las mismas había una diferenciación, la cual dependía del uso y destino de las mismas. En este sentido se considera que los pueblos tenían un fundo legal, que comprendía el área destinada al caserío; las tierras de propios que servían para sufragar los gastos municipales; las tierras de común repartimiento, que eran parcelas familiares de uso individual; y los ejidos, que eran explotados de forma colectiva por los habitantes del pueblo (Knowlton, 1978, pp. 27-28; Fraser, 1972, p. 631). Otros estudios consideran que también existían tierras de santos y propiedad individual (Birrichaga, 2003, pp. 208-225; Mendoza, 2011, pp. 275-294, 297-207; Gutiérrez, 2002, pp. 13-15).

En algunos Estados como Michoacán y Jalisco desde los primeros años de la independencia se decretó legalmente la conversión de las tierras comunales de los pueblos a propiedad individual, es decir a propiedad absoluta (Knowlton, 1978; Cortés, 2013). En el Estado de México se pretendió hacer lo mismo, por ello se discutió en el Congreso Constituyente de 1824 la posibilidad de otorgar en propiedad individual las tierras comunales de los pueblos a los vecinos. Los diputados Benito Guerra y José María Jáuregui reconocieron la propiedad que los pueblos tenían sobre sus tierras (tierras de común repartimiento, tierras de cofradías y tierras comunes o ejidos); no obstante, dichas tierras debían ser repartidas entre los vecinos a título individual mediante un canon o renta. Por su parte, el diputado José María Luis Mora manifestó que los pueblos no podían ser propietarios, pues los únicos que podían serlo eran los ciudadanos; además, consideró que el Congreso tenía la facultad de discutir el destino de las tierras de los pueblos como mejor conviniera. Mora expuso que las tierras de los pueblos debían formar parte de los propios de los ayuntamientos, para que estos las arrendaran y así pudieran solventar sus gastos (Actas del Congreso Constituyente del Estado de México, 1824, pp. 390-391). 
El Congreso estatal finalmente determinó, mediante la expedición de la ley del 9 de febrero de 1825, que todas las tierras en propiedad comunal de los pueblos pasaban a formar parte de los propios del ayuntamiento. Esto sin importar que fuesen de común repartimiento, de santos o ejidos, pues repartir las tierras en propiedad individual entre los vecinos de los pueblos era una medida inviable, por no contar estos con los recursos necesarios para hacerlas productivas. De esta forma, las tierras de los pueblos debían ser repartidas ente los vecinos según sus necesidades bajo una contribución o arrendamiento (enfiteusis) a los ayuntamientos (Actas del Congreso Constituyente del Estado de México, 1824, pp. 390-391).

Este primer intento por adjudicar las tierras de los pueblos en propiedad individual no pudo llevarse a cabo, pero cambió la forma de acceder y distribuir la tierra. Si bien los pueblos conservaron la propiedad comunal de sus tierras, los ayuntamientos adquirieron la facultad de administrarlas y con ello el derecho de poder dar en arrendamiento pastos, montes y lagunas. En cuanto a las tierras de común repartimiento, los ayuntamientos adquirieron el derecho de repartirlas y obtener una contribución en efectivo o en especie.

Posteriormente, la Constitución del Estado de México de 1827 supeditó las actividades de los ayuntamientos a la vigilancia de los prefectos y subprefectos (autoridades estatales). ${ }^{14}$ Estas autoridades tenían la responsabilidad de: hacer que los ayuntamientos cumplieran con sus obligaciones, velar sobre la buena inversión de los fondos públicos de los pueblos y la buena administración de los bienes de comunidad, así como hacer el repartimiento de tierras y expedir los títulos de dominio (Colín, 1974, pp. 26-28). ¿Por qué otorgar títulos de dominio sobre tierras de común repartimiento? Sin duda, el otorgar un título de dominio modificaba la tenencia individual sobre la tierra. De esta forma, los gobiernos liberales poco a poco implementaron las ideas liberales sobre la propiedad.

A estas medidas legislativas se agregó el decreto estatal del 9 de mayo de 1833, mediante el cual se adjudicaron a los ayuntamientos para sus propios, los terrenos realengos o baldíos existentes en el territorio de sus municipalidades. El artículo 2. o determinó que: "El juez de hacienda de cada partido recibirá la correspondiente información acerca de los terrenos que sean realengos, y no habiendo justificado oposición, procederán a posesionar los respectivos ayuntamientos". En tanto que, el artículo 5. ${ }^{\circ}$ estableció que: "Los Ayuntamientos con acuerdo del síndico, arrendarán los terrenos. Dividiéndolos en porciones pequeñas para beneficiar a distintas familias" (Molina, 1970, p. 25).

El decreto del 9 de mayo de 1833 más que darles la posesión a los ayuntamientos, entendida en el sentido actual, lo que hizo fue darles la propiedad (propiedad corporativa), pues ambos artículos denotan el derecho municipal a ejercer el "dominio pleno" sobre dichas tierras (Molina, 1970, p. 44). No obstante, el 2 de junio de 1835 se derogó dicho decreto ordenando que:

Los terrenos de repartimiento que en virtud de dicha ley u otras disposiciones anteriores se hayan dado en arrendamiento, luego que se cumpla el término de éste volverán a repartirse conforme a las costumbres que estaban en uso en los pueblos antes de ellas (Molina, 1970, pp.43).

Con ello, se reconoció la propiedad comunal que los pueblos tenían sobre sus tierras; al igual que se reconoció en las ordenanzas municipales de 1845, cuando la Asamblea Departamental de México aclaró que los propios de los pueblos eran los bienes que estaban en pacífica posesión y que administraban los ayuntamientos (Birrichaga, 2003, p. 2199).

A partir del análisis de la legislación podemos mencionar tres aspectos. Primero, las tierras de común repartimiento se fueron conformando con diferentes tipos de tierras: tierras del fundo legal, tierras de cofradías, tierras de ejidos y tierras baldías; además de las ya existentes desde el periodo colonial. Segundo, los pueblos mantuvieron la propiedad comunal de sus tierras, pero algunas de ellas fueron repartidas individualmente a los vecinos sin tierra. Tercero, el derecho de los ayuntamientos a administrar las tierras de los pueblos ayudó, en algunos casos, a asumirse como propietarios de las tierras; sobre todo, de las de común repartimiento. 
Establecido lo anterior, no es raro encontrar que al expedirse la ley del 25 de junio de 1856 la mayoría de las tierras de común repartimiento, ubicadas en la municipalidad de Cuautitlán, fueran poseídas individualmente, heredadas y vendidas con independencia de terceros; es decir, sus formas de posesión y traspaso las asemejaban más bien a las de una propiedad individual (Neri, 2017, pp. 120-170). En otros lugares como Texcoco y Tepotzotlán sucedía lo mismo, ya que los vecinos poseedores de las parcelas de común repartimiento las consideraban como propias, por lo que con frecuencia las rentaban o vendían en un mercado abierto, en ocasiones con títulos de dominio y a veces con simples acuerdos verbales (Birrichaga, 2003, pp. 261-165; Pacheco, 2011, p. 21).

La historiografía muestra que la desamortización no tuvo efectos inmediatos y que empezó a realizarse con eficacia después del Imperio de Maximiliano en 1867. Por ejemplo, Antonio Escobar (2001), para el caso de las Huastecas, encuentra que la desamortización empezó a llevarse a cabo después de 1867 (p. 180). Daniela Marino (2006) menciona que para diversas zonas del Estado de México la restauración de la república en 1867 marcó el inicio de la desamortización (pp. 195, 229). Gloria Camacho (2015) refiere que en Lerma y Ocoyoacac la desamortización de los propios de los ayuntamientos se dio en los meses de noviembre y diciembre de 1856, en tanto que la desamortización de los terrenos de común repartimiento se efectuó a partir de 1870, debido a que ya estaba presente la tradición de disfrutarlas individualmente (pp. 83-84, 86-89).

En el caso del valle de Cuautitlán, entre los meses de agosto y octubre de 1856, varios vecinos de las municipalidades de Cuautitlán, Tultitlán, Teoloyucan y San Miguel acudieron ante el juez de primera instancia del distrito de Cuautitlán a solicitar y realizar la adjudicación de sus parcelas de común repartimiento. Ante dicha autoridad, el presidente municipal en cumplimiento de la ley del 25 de junio de 1856 adjudicaba el terreno o los terrenos al posesionario. La persona a quien se le adjudicaba estaba obligada a pagarle al ayuntamiento el precio de la tierra a censo redimible sin plazo fijo; además, debía de pagar una alcabala por la traslación de dominio y hacer los gastos del contrato respectivo.

El hecho de que las tierras se hayan adjudicado a censo redimible no implicaba que la plena propiedad se adquiría hasta cubrir el costo total de la tierra, ya que la propiedad se obtenía mediante el acto jurídico por el que se transmitía. Este acto jurídico era la acción mediante la cual la corporación municipal se apartaba de la propiedad del terreno que enajenaba, y por la cual el adjudicatario adquiría la propiedad individual del mismo. De esta forma, la ley de desamortización convirtió a los que poseían tierras de común repartimiento en propietarios individuales otorgándoles una escritura de adjudicación, para comprobar su propiedad (Neri, 2017, p. 155).

En la municipalidad de Cuautitlán, como en algunas otras del valle, las adjudicaciones realizadas en el mes de agosto fueron pocas, pero de septiembre a octubre de 1856 se adjudicaron 583 terrenos de común repartimiento a 190 personas. El valor de todas las propiedades ascendía a 9525 pesos. En general, los vecinos de los pueblos y barrios de la municipalidad de Cuautitlán, solicitaron la privatización de 3 o 4 terrenos, y hubo a quien se le adjudicaron 7 y 8 terrenos; por ejemplo, el 9 de octubre de 1856 a Julián Ciriaco se le adjudicaron ocho terrenos de común repartimiento en el pueblo de Santa María Huecatitlla. ${ }^{15}$ El área de los terrenos variaba entre los $6889 \mathrm{~m} 2$ y los $15625 \mathrm{~m} 2$, muy pocas rebasaban los $27888 \mathrm{~m} 2$. Las siguientes gráficas muestran la cantidad de tierras desamortizadas en diferentes pueblos y barrios de la municipalidad de Cuautitlán. 
Figura 3. Adjudicaciones en la municipalidad de Cuautitlán (septiembre - octubre de 1856)
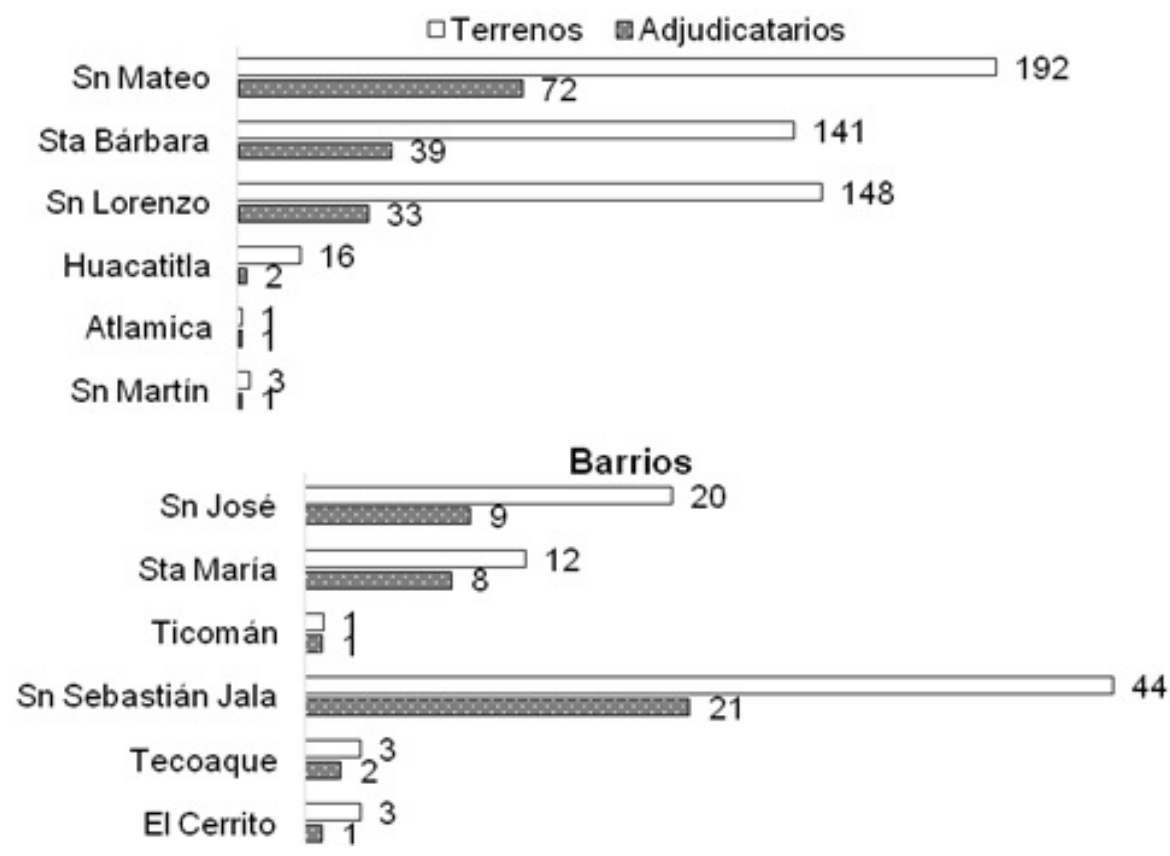

Fuente: Elaboración propia con base en distintas escrituras de adjudicación localizadas en el Archivo Histórico de Notarías del Estado de México. AHNEM/ Notaría 1/ Cayetano Gómez y Pérez/1856/ caja 3; AHNEM/

Notaría 1/ Cayetano Gómez y Pérez/1856/ caja 4; AHNEM/ Notaría 1/ Cayetano Gómez y Pérez/1856/ caja 5.

Si observamos la gráfica, y tomamos en cuenta la distribución del agua de la Pila Real de Atlamica, notamos que los pueblos en los que más adjudicaciones hubo fueron los que recibían mayor cantidad de agua para regar sus tierras: Santa Bárbara, San Mateo, San Lorenzo y San Sebastián. Las tierras de común repartimiento ubicadas en estos cuatro pueblos aprovechaban el agua a través de dos acequias: la de "Santa Bárbara" y la de "Guayapango". Los posesionarios de estos terrenos ya fueran de riego o temporal acudieron ante el juez de primera instancia a realizar el trámite de adjudicación, con base en la ley del 25 de junio de 1856.

En promedio, a cada vecino de Santa Bárbara se le adjudicación 3 o 4 terrenos. Por ejemplo, el 9 de octubre de 1856 a Esteban Jiménez se le asignaron cuatro terrenos de común repartimiento: un solar, una parcela de temporal y dos de riego; el mismo día a Petronilo Sánchez dieron tres terrenos: un solar y dos de riego; ${ }^{16}$ a Bonifacio Guzmán se le adjudicaron seis terrenos: un solar, tres tierras de temporal y dos de riego. ${ }^{17}$ En algunos casos, las escrituras de adjudicación no mencionan si las tierras eran de riego, como en el caso de Jesús Vargas, a quien se le adjudicaron cinco terrenos; no obstante, en los linderos aparecen las zanjas regadoras: ${ }^{18}$

La primera tierra arenosa, donde está situada el sitio [solar] tiene por el oriente veinte varas, linda con Pedro de Verónica; por el norte también veinte varas, linda con vereda del camino; por el poniente dieciséis varas linda con vereda del camino y por el sur veinte varas linda con zanja madre. ${ }^{19}$

La gráfica nos muestra que San Mateo y Santa Bárbara fueron los pueblos en donde hubo más parcelas de común repartimiento desamortizadas; no obstante, en otros pueblos también se adjudicaron varias tierras como en San Lorenzo y San Sebastián. El considerable número de parcelas desamortizadas en manos de una sola persona comprueba que antes de 1856 ya existía la compraventa de tierras; incluso, comerciantes extranjeros como José Pico Cerro compraron tierras dentro del sistema de riego.

El 9 de octubre de 1856 la forma de adjudicar las tierras de común repartimiento dio un giro importante (Neri, 2017, pp. 113-114), ya que mediante una circular federal se estableció que todo terreno que no pasara de 200 pesos, dentro de los cuales estaban los de común repartimiento, quedaba exento de hacer la 
adjudicación ante notario y de pagar alcabala o derecho alguno; es decir, no había necesidad de otorgarles escritura de adjudicación, pues para constituirlos dueños y propietarios en toda forma del terreno bastaba con el título que les daba la autoridad política (presidente municipal o jefe político) (Labastida, 1893, pp. 13-14). De esta manera, solo tenían que cubrir el valor de la tierra mediante el censo redimible; no obstante, este censo fue eliminado en el decreto del 20 de octubre de $1868 .{ }^{20}$ Si bien se eximió a los propietarios de terrenos de común repartimiento del censo redimible, el artículo $2{ }^{\circ}$ de dicho decreto estableció una contribución municipal anual del $3 \%$ anual sobre el valor del terreno, que en 1875 aumentó a $8 \%$ al millar; es decir, el impuesto subió considerablemente. ${ }^{21}$

Podemos decir que las tierras de común repartimiento ubicadas en la municipalidad de Cuautitlán fueron fáciles de desamortizar, debido a que ya eran disfrutadas individualmente y a que contaban con características propias de la propiedad individual; pero, además, porque estaban ubicadas dentro de un sistema de riego que las hacía potencialmente propicias para el desarrollo de una agricultura comercial como sucedió en Papantla o Cuicatlán. ${ }^{22}$

En el caso de la municipalidad de Cuautitlán, y en general en el valle de Cuautitlán, la desamortización de tierras de común repartimiento inició antes del imperio de Maximillo; se detuvo durante este periodo, pero se reinició en 1867. Después de este año se observa un acaparamiento de las tierras desamortizadas por parte de comerciantes nacionales y extranjeros. Los nuevos propietarios individuales de la municipalidad de Cuautitlán no quisieron o no pudieron conservar sus tierras desamortizadas y decidieron venderlas a hacendados y rancheros.

En suma, durante la primera mitad del siglo XIX los rasgos que definían las tierras de común repartimiento dentro de la propiedad comunal fueron cambiando, debido a factores legales y sociales; en muchos casos, estas tierras dejaron de ser concebidas como tierras comunales que pertenecían el pueblo en su conjunto y que eran distribuidas a las familias para su subsistencia, al grado de que los poseedores se asumían como propietarios de las mismas. Hasta el momento podemos decir que las tierras de común repartimiento antes de ser adjudicadas conforme a la ley del 25 de junio de 1856 eran propiedad de los pueblos, pero poseídas individualmente por los vecinos; eran distribuidas por el presidente municipal o el prefecto y podían ser vendidas en un mercado abierto con independencia de terceros. Una vez adjudicadas conforme a la Ley Lerdo las tierras de común repartimiento se convirtieron en propiedades individuales de pleno dominio, que conservaron el nombre de tierras de común repartimiento únicamente para identificarlas como aquellas tierras adjudicadas y que pagaban un censo redimible al ayuntamiento.

Las tierras de común repartimiento, después de ser desamortizadas, adquirieron el carácter de propiedades individuales; mismas que a finales del siglo XIX empezaron a ser concebidas como propiedades privadas. En este sentido, la ley del 25 de junio de 1856, y otras disposiciones legales, ayudaron a establecer diferencias entre posesión y propiedad.

\section{LA FORMACIÓN DE LOS RANCHOS}

El reparto de aguas de 1762 de la Pila Real de Atlamica registra la existencia de siete ranchos, pero desconocemos la actividad económica de los mismos y si estaban anexos a una hacienda o eran independientes. Algunos autores como Ramón María Serrera (1991) y Rodolfo Fernández (1999) consideran que durante la época colonial el "Rancho" era una propiedad más pequeña que la hacienda, en ocasiones perteneciente a la misma, pero que se trabajaba de manera independiente por el ranchero y su familia. Los rancheros, generalmente, se dedicaban a la ganadería o se especializaban en algún cultivo y eventualmente contrataban mano de obra.

Para el siglo XIX poco o nada se ha escrito sobre los rancheros de la cuenca de México, mucho menos sobre los del valle de Cuautitlán. Las estadísticas recopiladas por Miño y Vera sobre la cantidad de 
ranchos existentes en las trece municipalidades que integraban el valle son imprecisas. Por ejemplo, en 1870 únicamente se registra la existencia de 13 ranchos (Miño y Vera, 1998, pp. 175-199). No obstante, la documentación de archivo muestra datos distintos, pues solo en la municipalidad de Zumpango registramos la existencia de 46 ranchos; en tanto que en la municipalidad de Cuautitlán encontramos la presencia de 9 ranchos. En este sentido, consideramos que la legislación estatal, abordada en el apartado anterior, ayudó a que en algunos lugares del valle de Cuautitlán se fueran estableciendo distintos ranchos mediante la renta de tierras de propios a los ayuntamientos, los cuales se consolidaron con las leyes liberales de la reforma, como bien lo ha señalado David Brading (1988).

Sabemos de la existencia de ranchos en el valle de Cuautitlán, pero no conocemos sus características, como sí las sabemos para otras regiones de México. Por ejemplo, en Querétaro los rancheros eran dueños de pequeñas propiedades que habían pertenecido a una hacienda y muchos eran al mismo tiempo administradores de la hacienda, medieros o peones libres de la misma (García, 1994, p. 206). Frans Schryer (1994), para el caso de la Huasteca Hidalguense, nos dice que durante el siglo XX mestizos y otras personas de fuera se insertaron paulatinamente en la posesión de terrenos comunales de la región de Huejutla. Estas personas lograron formar ranchos y establecer negocios (p. 212).

Debido a las distintas características de los rancheros y los ranchos resulta difícil establecer una definición precisa sobre ellos, pero de manera general por ranchero se entendía a la persona que habitaba o poseía un rancho; lo cual incluye distintas figuras: el pequeño propietario, el arrendatario, el jornalero y el citadino. Respecto a la extensión del rancho consideramos que no es una característica que deba definirlo, pues en el valle de Cuautitlán la extensión del rancho podía variar considerablemente: los había de 20 hectáreas y de hasta 150 hectáreas; es decir, la cantidad de tierra no definía al rancho.

Ahora bien, ¿cómo es que los ranchos empezaron a establecerse en el sistema de riego de la Pila Real de Atlamica? Antes de 1856, comúnmente, la venta de tierras de común repartimiento se hacía entre los vecinos; pero una vez desamortizadas las tierras de común repartimiento, comerciantes nacionales y extranjeros empezaron a figurar en el mercado de tierras comprando una, dos, diez o más fracciones de tierra. No era lo mismo comprar dos o tres tierras de común repartimiento, como lo hacían algunos vecinos de los pueblos, que invertir grandes cantidades de dinero sobre tierras de común repartimiento desamortizadas para destinarlas a actividades comerciales. En este sentido, los comerciantes vieron las ventajas que representaba comprar tierras desamortizadas (propiedades individuales) dentro del sistema de riego de la Pila Real de Atlamica y empezaron a comprarlas, como fue el caso de Joaquín Andonaegui, Jesús Huesca, José Ampudia, Ramón Ampudia y José Pico Cerro. Veamos algunos casos.

El 1 de abril de 1879 Pilar Santos Marroquín, natural de Zumpango y vecino de Cuautitlán, vendió el "Rancho la Era" a Joaquín Andonaegui y Martachi en 2000 pesos. Pilar Santos Marroquín formó el rancho con tierras de común repartimiento que le fueron adjudicadas conforme a la ley del 25 de junio de 1856 y otras, de la misma clase, que compró a diversos vecinos de Santa Bárbara y Huecatitla. Los terrenos, en conjunto, sumaban un valor de 747 por adjudicación; es decir que Pilar Santo Marroquín vendió los terrenos a más del doble respecto a su valor original. ${ }^{23}$ Probablemente los terrenos aumentaron su valor debido a que Marroquín construyó edificios, infraestructura hidráulica, o a que vendió los terrenos sembrados con algún producto; aunque no tenemos evidencia de ello.

Con esta transacción, Joaquín Andonaeguí, natural de la Ciudad de México y dueño de la hacienda de Cuamatla, adquirió un rancho formado a partir de tierras de común repartimiento desamortizadas. Podemos notar que, aunque los propietarios se refieren a las tierras con el nombre de "común repartimiento", en realidad ya se trata de propiedades individuales.

Otro caso es el del Rancho de Guadalupe. El 1 de marzo de 1889 el coronel Jesús Huesca, natural de Puebla y residente en la ciudad de México, legalizó ante notario la compra de trece terrenos de común repartimiento que hizo a distintos vecinos de Santa Bárbara y Santa María Huacatitla, pagando por ellos un total de 1016 pesos. ${ }^{24}$ Desconocemos las fechas en que se hizo la compra de cada uno de los terrenos, pero con estos terrenos 
Huesca formó el Rancho de Guadalupe, en los que construyó una fábrica material formada con tres piezas de habitación, una galera para troje y un corral. El 2 de marzo de 1889 Jesús Huesca vendió en 6000 pesos el rancho a José Ampudia, comerciante español, natural de la provincia de Asturias. ${ }^{25}$ Conviene indicar que en el segundo contrato de compraventa Huesca mencionó que era dueño en pleno dominio y propiedad de las tierras de labor y riego; es decir, ya no se refiere a ellas como tierras de común repartimiento.

Jesús Huesca vendió el rancho con todo lo existente en él: la fábrica, los utensilios de labranza, las semillas, siembras, aperos; así como con todos sus usos, costumbres, derechos y servidumbres. Ello implicaba el derecho a continuar utilizando las aguas de la Pila Real de Atlamica para regar sus tierras. En caso de no cubrir el pago estipulado en el plazo de dos años o recisión del contrato, Ampudia debía regresarle el rancho Jesús Huesca con los aperos y enceres existentes al momento de la venta; los cuales eran: 25000 magueyes de vara, cuarenta vacas de vientre, veinte mulas de tiro, la casa troje, los terrenos en estado de uso y el menaje de casa.

El hecho de que Jesús Huesca haya vendido el rancho un día después de haber legalizado la compra de los terrenos no es congruente con el aumento del precio y la construcción de la fábrica, la existencia de las vacas, las mulas y todo lo que en ella había. Seguramente, lo que sucedió es que Huesca compró los trece terrenos en distintos momentos, pero sin realizar el contrato de compraventa ante notario, por lo que cuando decidió vender el rancho a Ampudia tuvo que legalizar la compra de los trece terrenos.

José Ampudia, propietario del Rancho de Guadalupe, decidió formar una sociedad con Ramón Ampudia propietario del Rancho de Santa Elena; la que prosperó y continuó comprando terrenos de común repartimiento. ${ }^{26}$ Como vemos, los ranchos se establecieron en un área rural, las tierras fueron adquiridas por personas externas a los pueblos, los dueños residían en las tierras y las trabajaban; éstas características coinciden con las observadas por Odile Hoffmann (1994) para el caso de los rancheros del centro de Veracruz (p. 222), pero contrastan con las mostradas por Tortolero (1995), quien menciona que los dueños de los ranchos en Chalco no vivían en su propiedad, y que al parecer eran terratenientes que poseían otras propiedades en la república (p. 195).

Uno de los casos más significativos es el del Rancho el Peral. José Pico Cerro era comerciante de origen español y vecino del pueblo de Cuautitlán, compró tierras de común repartimiento en los linderos del pueblo de Santa Bárbara y San Mateo Ixtacalco antes de expedirse la ley de desamortización; debido a ello, el diecisiete de septiembre de 1856 el presidente municipal de Cuautitlán le adjudicó una parcela conforme a la ley del 25 de junio de $1856 .{ }^{27} \mathrm{El}$ dos de octubre del mismo año le fue adjudicado otro terreno en Santa Bárbara, pero en esta escritura de adjudicación se mencionó que:

comparecieron el señor presidente del ilustre ayuntamiento de esta cabecera Don Cosme Quezada vecino de esta cabecera y el ciudadano José Pico Cerro, vecino de la misma a quien doy fe conozco, y el primero dijo que en cumplimiento de la ley del veinticinco de junio último vende al segundo un terreno de labor, y en el que se halla situada la casa del mismo Pico Cerro, en el paraje nombrado el Peral [cursivas añadidas]. ${ }^{28}$

El documento muestra el cambio de residencia de José Pico Cerro, quien primero vivía en el pueblo cabecera de la municipalidad, es decir, en Cuautitlán, y después en el paraje llamado el Peral. A partir de 1857 José Pico Cerro empezó a comprar tierras de común repartimiento desamortizadas; por ejemplo, el 7 de mayo de 1857 compró cuatro tierras a los vecinos del pueblo de Santa Bárbara, en cuya transacción se mencionó que era vecino del Rancho el Peral: "Comparecieron Manuel Villareal, Don Clemente Sánchez, Don Tiburcio Peña, Don Gabino Prestado y el ciudadano español José Pico Cerro (...) los cuatro primeros vecinos del pueblo de Santa Bárbara, el señor Pico del Rancho el Peral”. ${ }^{29}$ Aquí podemos observar el cambio de "paraje" a "rancho".

José Pico Cerro continuó comprando tierras de común repartimiento a los vecinos de Santa Bárbara, hasta sumar veintinueve parcelas de común repartimiento; entre ellas, destaca la compra de diez terrenos que hizo el 18 de septiembre de 1857 a nueve vecinos de dicho pueblo. Por ejemplo, a Petronilo Sánchez le habían sido adjudicados tres terrenos en la cantidad de 66 pesos conforme a la ley del 25 de junio de 1856 . De 
estos terrenos vendió uno en 58 pesos a José Pico Cerro, habiendo recibido 25 pesos y quedando los 33 pesos restantes a favor del ayuntamiento. ${ }^{30}$ Las ventas de tierras hacen evidente el alza en el precio de las tierras desamortizadas y el que los vecinos contaban con tres, cuatro o cinco parcelas, lo que hace suponer que difícilmente los vecinos vendieron sus tierras de común repartimiento por no poder pagar el valor de la tierra al ayuntamiento. No obstante, no descartamos la posibilidad de que los vecinos hayan vendido una de sus tierras para cubrir el valor de las otras.

De los nueve vecinos que vendieron tierras a Pico Cerro, únicamente Pedro Salgado mencionó que la tierra que enajenaba era de riego. La escritura de compraventa del terreno vendido por Petronilo Sánchez no menciona si era de riego, pero al remitirnos a la escritura de adjudicación del 9 de octubre de 1856 y verificar las colindancias se puede constatar que el terreno, efectivamente, era de riego. Sin duda, el agua fue un factor importante en la compraventa de tierras de común repartimiento. Resulta difícil pensar que sólo una fuera de riego, si las tierras estaban ubicadas en el mismo lugar. No obstante, hay que recordar que varias tierras eran de temporal y fueron los diferentes dueños del Rancho el Peral los que las abrieron al riego.

El 14 de enero de 1875 José Pico Cerro y su hijo José Pico San Martín vendieron el Rancho el Peral a Juan B. Andonaegui y Martachi, comerciante mexicano. Posteriormente, el 29 de septiembre de 1887 Manuela López, viuda de Andonaegui, vendió el rancho a José Piñera, comerciante de origen español. La venta del rancho se realizó junto con los usos de agua que poseía para sus riegos, con todas sus entradas y salidas, regalías y servidumbres. ${ }^{31}$ Posteriormente, el cuatro de febrero de 1895, Julio Roux compró el Rancho el Peral y tuvo que enfrentar conflictos por el uso del agua con los vecinos de Santa Bárbara.

En abril 1896 Julio Roux y los vecinos de Santa Bárbara establecieron un contrato ante el jefe político sobre la forma de disfrutar el agua, para así solucionar las desavenencias por el líquido. En enero de 1897 el contrato fue escriturado ante el juez de distrito de Cuautitlán. En este convenio, el síndico del ayuntamiento de Cuautitlán, como representante de los vecinos de Santa Bárbara, y Julio Roux, dueño del Rancho el Peral, acordaron que el Rancho el Peral en lugar de usar simultáneamente y en partes iguales las aguas junto con todos los vecinos dueños de terrenos de Santa Bárbara, aprovecharía el volumen total a través de las respectivas tomas durante veinticuatro horas consecutivas; desde las seis de la mañana de todos los primeros días en que iniciaban las tandas del pueblo de Santa Bárbara, quedando los cinco días restantes en favor de dicho pueblo. ${ }^{32}$

De esta forma se modificó la servidumbre que el Rancho el Peral disfrutaba sobre las aguas de riego, cuyas aguas partían de la taza repartidora de Atlamica y corrían a través de la zanja de "Santa Bárbara" y de "San Mateo" (Uayapango) hasta los terrenos de dicho pueblo. Esta distribución hace evidente que el reparto de aguas de la Pila Real de Atlamica, establecido a finales del periodo colonial, ya no tenía nada que ver con la distribución del agua realizada durante la segunda mitad del siglo XIX. También nos deja ver que el agua continuaba estando en propiedad de los pueblos y administrada por el ayuntamiento de Cuautitlán.

En 1905 la señora Trinidad Uribe compró el Rancho el Peral en 71274 pesos, el cual reportaba 1074 pesos a favor del ayuntamiento por tratarse de terrenos de común repartimiento. En la venta quedaron comprendidas las construcciones: casas, corrales y las obras ejecutadas para la industria agrícola por los anteriores dueños, así como los derechos para disfrutar de las aguas con que se regaban los terrenos sembrados de alfalfares. En 1911, Francisco Uribe, albacea de la testamentaría de Trinidad Uribe, vendió en 65000 pesos 155 hectáreas del Rancho el Peral a los hacendados Benjamín Zanatta y Ángela Zanatta, quedándose la parte vendedora únicamente con ocho terrenos que formaban el predio Puente Grande. ${ }^{33}$

En suma, podemos darnos cuenta cómo el Rancho el Peral fue incrementando su área cultivable mediante la compra de tierras de común repartimiento que los diferentes propietarios del rancho realizaron a los vecinos de Santa Bárbara. Este mismo fenómeno se ve con los otros ranchos ya mencionados. Los distintos propietarios de los ranchos ubicados en la municipalidad de Cuautitlán, poco a poco, fueron comprando terrenos y construyendo infraestructura hidráulica para poder regar la mayor cantidad de terrenos. ${ }^{34}$ En las parcelas regables se fue introduciendo, principalmente, la siembra de alfalfa, pero también se continuó 
cultivando maíz y trigo. Además, los dueños de los ranchos también introdujeron ganado vacuno para la producción de leche. ${ }^{35}$

De esta manera, la compra de tierras, el sistema de riego, el cultivo de forrajes y la introducción de ganado fueron actividades que se vieron reflejadas en el surgimiento de una industria ganadero-lechera en el valle de Cuautitlán. Skerrit (1993), para el caso de Veracruz, menciona que la ganadería se presentaba como la actividad rectora del ranchero; aunque se alternaba con actividades agrícolas y comerciales (p. 12). En el valle de Cuautitlán, muy probablemente, la actividad lechera llegó a ser de suma importancia dada su proximidad con la Ciudad de México y las oportunidades de comercialización que ofrecía la región.

No obstante, habría que ver que pasó después de 1911, ya que a partir de este año el Rancho el Peral y otros tantos, incluidas las haciendas, empezaron a sufrir desmembraciones debido al inicio de la reforma agraria. Por ejemplo, en 1917 el ejido de San Mateo Ixtacalco pretendía ser constituido con 149 hectáreas del Rancho el Peral, 620 hectáreas de la Hacienda el Sabino, 273 hectáreas de la hacienda de Jaltipa, 586 hectáreas de la hacienda de San Mateo y con tierras de los ranchos La Soledad y El Socorro (Neri, 2017, p. 271); en tanto que en 1918 el ejido del pueblo de Santa Bárbara pretendía ser constituido con 55 hectáreas del Rancho el Peral y con 48 hectáreas de la hacienda de San José Puente Grande. ${ }^{36}$

Cuando los pueblos presentaron sus solicitudes para que se les dotara de ejidos, los propietarios de las haciendas y ranchos afectados argumentaron entre otros aspectos que, de llevarse a cabo la dotación a los diferentes pueblos del valle de Cuautitlán, la industria lechera resultaría seriamente afectada.

\section{CONSIDERACIONES FINALES}

Hablar de la desamortización y el mercado de tierras en el sistema de riego de la Pila Real de Atlamica significa remontarnos al periodo colonial y la primera mitad del siglo XIX; primero, para entender la distribución y administración del agua; y segundo, para comprender la legislación en torno a las tierras de común repartimiento. En general, con este texto hemos querido plantear que la propiedad de las tierras de común repartimiento cambió poco a poco y no con el simple hecho de haberse adjudicado conforme a la ley del 25 de junio de 1856; ya que consideramos que el cambio de propiedad es un proceso continuo, vinculado estrechamente a las formas en que los individuos acceden, poseen y disfrutan de los recursos.

En un espacio como el sistema de riego de la Pila Real de Atlamica, no podemos restringir la transición entre tierras comunales y propiedad individual al hecho de haber sido adjudicadas las tierras conforme a la Ley Lerdo. Por otro lado, también debemos tomar en cuenta aspectos como la costumbre entre los vecinos de vender la tierra, el hecho de que muchos vecinos se consideraban propietarios individuales de las tierras y la pérdida del sentido comunal sobre las tierras de común repartimiento. Pudimos darnos cuenta que, hasta antes de 1856, la legislación no era clara respecto a la propiedad individual; en distintos casos lo que definió este tipo de propiedad fueron las formas de acceder y disfrutar de las tierras. No obstante, consideramos que la Ley Lerdo sirvió para dar claridad sobre lo que implicaba la posesión y la propiedad.

Es claro que las particularidades del sistema de riego aunadas a la ley del 25 de junio de 1856 propiciaron una rápida desamortización de las tierras de común repartimiento y el acaparamiento de las mismas por parte de los rancheros; sobre todo, en aquellos pueblos que hasta 1856 habían logrado mantener las tierras de común repartimiento fuera del alcance de los hacendados. En este orden, la presencia del recurso hídrico explica \#en cierta medida \# que comerciantes nacionales y extranjeros se interesaran en las tierras de común repartimiento y que estas hayan incrementado su valor comercial. No obstante, hace falta profundizar en los ranchos y la sociedad ranchera que se instaló en el valle de Cuautitlán. De igual manera, hay que analizar la industria lechera que se desarrolló en dicho valle y sus vínculos comerciales con la ciudad de México.

Conviene precisar que, contrario a lo establecido por la historiografía clásica, los vecinos de la municipalidad de Cuautitlán no perdieron sus tierras debido a despojos, extorciones u otros mecanismos ilegales, sino mediante mecanismos de mercado que las reformas liberales buscaron, precisamente, alentar 
para fomentar un uso productivo de la tierra. En suma, podemos decir que en el sistema de riego de la Pila Real de Atlamica los aspectos naturales, económicos y legales dieron oportunidad a un proceso de concentración de tierras y aguas, permitiendo un cambio en la propiedad de las tierras de común repartimiento.

\section{REFERENCIAS}

Aboites, L. (1998). El agua de la nación. México: Centro de Investigaciones y Estudios Superiores en Antropología Social.

Actas del congreso Constituyente del Estado de México (1824). Tomo 2. Toluca: Imprenta de Martín Rivera.

Birrichaga, D. (2003). Administración de tierras y bienes comunales. Política, organización territorial y comunidad de los pueblos de Texcoco, 1812-1857 (Tesis de doctorado), El Colegio de México, México.

Brading, D. (1988). Haciendas y Ranchos del Bajio: León 1700-1860. México: Grijalbo.

Camacho, P. G. (2015). De la desamortización a la reforma agraria, 1856-1930. Los pueblos y sus tierras en el sur del valle de Toluca. Toluca: Universidad Autónoma del Estado de México.

Castañeda, G. (2005). Las aguas de Atlixco. Estado, haciendas, fábricas y pueblos, 1880-1920. México: Centro de Investigaciones y Estudios Superiores en Antropología Social, Colegio de México, Comisión Nacional del Agua.

Colín, M. (comp.). (1974). Constitución Política del Estado Libre y Soberano de México. En M. Colín, Constituciones del Estado de México 1827, 1861, 1870, 1917. México: Biblioteca Enciclopédica del Estado de México.

Cortés, J. C. (2013). La desamortización de la propiedad indígena en una provincia mexicana. Los fines y efectos de la Ley de 1827 sobre reparto de tierras comunales en Michoacán. Relaciones, 34(134), 263--301.

Escobar, A. (2001). La estructura agraria en las Huastecas 1880-1915. En A. Escobar y T. Rojas (coords.), Estructuras y formas agrarias en México del pasado y del presente (pp. 77-196). México: Registro Agrario Nacional, Archivo General Agrario, Centro de Investigación y Estudios Superiores en Antropología Social, México.

Escriche, J. (1851). Diccionario razonado de legislación y jurisprudencia. París: Librería de Rosa-Bouret y C.

Fernández, R. (1999). Mucha tierra y pocos dueños: estancias, haciendas y latifundios avaleños. México: Instituto Nacional de Antropología e Historia.

Fraser, D. (1972). La política de desamortización en las comunidades indígenas, 1850-1872. Historia Mexicana, 21(4), 615-652.

Garay, F. (1888). El Valle de México. México: Oficina Tipográfica de la Secretaria de Fomento.

García, L. J. (2007). Desamortización civil, mercado de tierras y resistencia indígena en el municipio de Atlazan, Veracruz: 1856-1913, (Tesis de licenciatura). Universidad Veracruzana, Xalapa.

García, M.E. (1994). Conformación del poder político de los rancheros en Querétaro (1920-1930). En E. Barragán, O. Hoffmann, T. Linck, y D. Skerritt (coords.), Rancheros y sociedades rancheras (pp. 201-210). Morelia: El Colegio de Michoacán.

Gobierno del Estado de México. (1848). Decreto no. 36 del 9 de febrero de 1825. Para la organización de ayuntamientos del Estado. En Colección de decretos y órdenes del Congreso Constituyente del Estado Libre y Soberano de México (pp. 44-54). Tomo 1. Toluca: Imprenta de Quijano.

Gutiérrez, A. (2002). El proceso agrario en las huastecas hidalguense y veracruzana, 1825-1874. Sotavento. Revista de Historia, Sociedad y Cultura, 11, 9-38.

Hoffmann, O. (1994). Rancheros y notables en Veracruz: su actuación política en las sociedades locales. En E. Barragán, O. Hoffmann, T. Linck y D. Skerritt (coords.), Rancheros y sociedades rancheras (pp. 219-136). Morelia: El Colegio de Michoacán.

Knowlton, R. (1978). La individualización de la propiedad corporativa en el siglo XIX. Notas sobre Jalisco. Historia Mexicana, 28(1), 24-61.

Kourí, E. (2013). Un pueblo dividido. Comercio, propiedady comunidad en Papantla, México. México: Fondo de Cultura Económica, El Colegio de México. 
Labastida, L. G. (1893). Colección de leyes, decretos, reglamentos, circulares, órdenes y acuerdos relativos a la desamortización de los bienes de corporaciones civiles y religiosas y a la nacionalización de los que administraron las últimas. México: Tipografía de la oficina impresora de estampillas de palacio nacional.

Margadant, G. (1989). El agua a la luz del derecho novohispano. Triunfo de realismo y flexibilidad. Anuario Mexicano de Historia del Derecho, 1. Recuperado de https://revistas-colaboracion.juridicas.unam.mx/index.php/anuariomexicano-historia-der/article/view/29399/26522

Marino, D. (2006). La modernidad a juicio: Los pueblos de Huixquilucan en la transición jurídica (Estado de México, 1856-1911) (Tesis de doctorado). El Colegio de México, México.

Mendoza, É. (2005). Distrito político y desamortización: resistencia y reparto de la propiedad comunal en los pueblos de Cuicatlán y Coixtlahuaca, 1856-1900. En R. Falcón (coord.), Culturas de pobreza y resistencia. Estudios de marginados, proscritos y descontentos México, 1804-1910 (pp. 209-235). México: El Colegio de México, Universidad Autónoma de Querétaro.

Mendoza, É. (2007). Privatización de la propiedad comunal y crecimiento agrícola en la región de la cañada. El distrito político de Cuicatlán, 1890-1910. En C. Sánchez (coord.), La desamortización civil en Oaxaca (pp. 103-134). Oaxaca: Universidad Autónoma Metropolitana, Universidad Autónoma “Benito Juárez" de Oaxaca.

Mendoza, É. (2011). Municipios, cofradias y tierras comunales. Los pueblos chocholtecos de Oaxaca en el siglo XIX. México: Centro de Investigaciones y Estudios Superiores en Antropología Social, Universidad Autónoma Metropolitana-Unidad Azcapotzalco, Universidad Autónoma “Benito Juárez” de Oaxaca, Oaxaca.

Mendoza, É. (2017). Tierras de común repartimiento y pequeña propiedad en San Juan Teotihuacán, Estado de México, 1856-1940. Historia Mexicana, 66(4), 1961-2011.

Menegus, B. (1995). Ocoyoacac- una comunidad agraria en el siglo XIX. En Lecturas de Historia Mexicana. Problemas agrarios y propiedad en México, siglos XVII y XIX (pp. 144-189). México: El Colegio de México.

Menegus, B. (1999). La desamortización de bienes comunales y municipales en el Valle de Toluca (1800-1845). En M. del P. Iracheta y D. Birrichaga (comps.), A la sombra de la primera república federal. El Estado de México, 1824-1835 (pp. 279-299). Zinacantepec: El Colegio Mexiquense.

Menegus, B. (2001). Los bienes comunales de los pueblos de indios a finales del periodo colonial. En A. Escobar y T. Rojas (coords.), Estructuras y formas agrarias en México, del pasado y del presente. México: Centro de Investigaciones y Estudios Supriores en Antropología Social.

Meyer, M. (1997). El agua en el sureste hispánico. Una historia social y legal (1550-1850). México: Instituto Mexicano de Tecnología del Agua. Centro de Investigaciones y Estudios Superiores en Antropología Social.

Miño, G. M., y Vera, B. M. (1998). Estadísticas para la historia de la población del Estado de México 1826-1910. Zinacantepec: El Colegio Mexiquense, Consejo Estatal de la Población.

Molina, A. A. (1970). Breve estudio Para la Determinación Jurídica de los Bienes Municipales Llamados de Común Repartimiento. Toluca: Gobierno del Estado de México.

Morlán, F. L. (2012). Saneamiento del Río Cuautitlán en el tramo Cortina Presa Guadalupe - Residencial La Luz (Tesis de maestría). Instituto Politécnico Nacional, México.

Neri, G. P. (2017). Entre montes y lagunas. Desamortización y mercado de tierras en la subcuenca del rio Cuautitlán 1856-1917 (Tesis de doctorado en Historia). Centro de Investigaciones y Estudios Superiores en Antropología Social, Mérida.

Neri, G. P. (2011). Las sociedades agricolas en el Estado de México durante el Porfiriato: transformación de la propiedad de los pueblos indígenas (Tesis de maestría en Estudios Históricos). Facultad de Humanidades-Universidad Autónoma del Estado de México, Toluca.

Orozco, M. (1864). Memoria para la Carta Hidrográfica del Valle de México. México: Imprenta de A. Boix, a cargo de Miguel Zornoza.

Pacheco, M. A. (2011). La Ley Lerdo y su aplicación en Tepotzotlán, Estado de México. Historia Agenda, (25), 15-24.

Quezada, J. T. (1996). Reforma y cambio en la estructura de la tierra en México: el caso de la desamortización civil y privatización de tierras de común repartimiento en la Municipalidad de Metepec, (Tesis de licenciatura). Facultad de Humanidades-Universidad Autónoma del Estado de México, Toluca. 
Reséndiz, Y. (1999). Conflictos por la tierra y el agua en la jurisdicción de Cuautitlán 1750-1820 (Tesis de licenciatura). Escuela Nacional de Antropología e Historia, México.

Sandre, I. (2007). Del derecho colonial al derecho municipal: la distribución de las aguas del río Cuautitlán, 1762-1914. Boletín del Archivo Histórico del Agua, 12(3), 37-49.

Sandre, I. (2012). Entre la ley y la costumbre. Tradición y poder local en la gestión del sistema de riego del río Cuautitlán (Tesis doctoral). Universidad Autónoma Metropolitana, México.

Schryer, F. (1994). Huasteca Hidalguense: región ranchera con indígenas. En E. Barragán, O. Hoffmann, T. Linck y D. Skerritt (coords.), Rancheros y sociedades rancheras (pp. 211-218). Morelia: El Colegio de Michoacán.

Serrera, R. M. (1991). Guadalajara ganadera. Estudio regional novohispano (1760-1805). Guadalajara: Ayuntamiento de Guadalajara.

Skerrit, G. D. (1993). Rancheros sobre tierra fértil. Jalapa: Universidad Veracruzana.

Tortolero, A. (1995). De la coa a la máquina de vapor. Actividad agricola e innovación tecnológica en las haciendas mexicanas: 1880-1914. México: El Colegio Mexiquense, Siglo XXI.

Venegas, A. (1923). Monografía del Estado de México. En Documentos relativos al Estado de México. Recuperado de http://cdigital.dgb.uanl.mx/la/1080013604/1080013604_08.pdf(consultado el 15 de octubre de 2017).

\section{Notas}

1 AHA/ Aguas Nacionales/ caja 18/ exp. 212/ leg. 1/ f. 72.

2 Cartas topográficas del INEGI: E14A29 y E14A28.

3 En 1888 Francisco Garay manifestó que, desde tiempos de los aztecas, las aguas del río Cuautitlán eran las más abundantes de la Cuenca de México; debido a ello había constantes desbordamientos que inundaban los pueblos de la región y la capital (p. 13).

4 Las aguas del río Cuautitlán no siempre siguieron este curso. Hasta antes de 1607 estas aguas se quedaban y consumían en el gran lago de la Cuenca de México, pero debido a las constantes inundaciones originadas por la gran cantidad de agua que descendían por el río Cuautitlán las autoridades españolas decidieron desviar su cauce en 1607 (Garay, 1888, pp. 37, 47).

5 A AHA/ Aprovechamientos Superficiales/ caja 264/ exp. 6345/ fs. 1-15 y 34; AHA/ Aguas Nacionales/ caja 18/ exp. 212/ leg. 1/ fs. 1-2v.

6 AHA/ Aprovechamientos Superficiales/caja 1410/ exp. 19277/ f. 8.

7 Meyer (1997) manifiesta que los repartimientos de aguas eran un mecanismo judicial para resolver los conflictos. Estos repartimientos, al igual que las mercedes, otorgaban derechos legales sobre el agua a los beneficiarios (pp. 144-145).

8 Por ejemplo, los pueblos de Tepotzotlán y la hacienda de Xuchimangas disfrutaron de forma exclusiva las aguas del río Tepotzotlán desde mediados del siglo XVI hasta finales del siglo XIX, con independencia de terceros; incuso, la Real Audiencia de México les concedió el dominio absoluto del agua. AHA/ Aprovechamientos Superficiales/ caja 4106/ exp. 55923/ fs. 55f-57v. En Atlixco los ribereños del río Cantarranas afianzaron el uso del agua desde el siglo XVII hasta finales del XIX (Castañeda, 2005, pp. 71, 79).

9 AHA/ Aguas Nacionales/ caja 18/ exp. 212/leg. 1/ f. 131.

10 AHA/ Aguas Nacionales/ caja 990/ exp. 12726/leg. 1/ fs. 60-61; AHA/ Aguas Nacionales/ caja 990/ exp. 12726/ leg. $1 /$ fs. 11.

11 AHA/ Aprovechamientos Superficiales/ caja 1410/ exp. 19277.

12 AHA/ Aguas Nacionales/ caja 1/ exp. 23/leg. $1 /$ fs. 7.

13 AHA/ Aguas Nacionales/ caja 27/ exp. 336/ leg. 1/ f. 1.

14 La Constitución de 1827 estableció la división del Estado en partidos, estos a su vez en distritos y los distritos en municipalidades. De acuerdo a dicha Constitución, la administración de los pueblos estaba a cargo de los prefectos en los partidos y de los subprefectos en los distritos.

15 AHNEM/Notaría 1/Gómez y Pérez/1856/caja 4/leg 4/fs. 182v.-184v.

16 AHNEM/ Notaría 1/ Cayetano Gómez y Pérez/ 1857/ caja 5/leg. 8/ fs. 80v-87.

17 AHNEM/ Notaría 1/ Cayetano Gómez y Pérez/1856/ caja 4/ leg.5/ fs. 90f.-92f.

18 AHNEM/ Notaría 1/ Cayetano Gómez y Pérez/1856/ caja 4/ leg.4/ fs. 193f.-195f.

19 AHNEM/ Notaría 1/Cayetano Gómez y Pérez/ 1856/ caja 4/ leg.4/ fs. 193f.-195f. 
20 Decreto núm. 78 del 12 de abril de 1875. Sobre terrenos de común repartimiento; AHMH/ Tierras/ vol. II/ año 1875/ caja $88 /$ exp. 4 .

21 Decreto núm. 78 del 12 de abril de 1875. Sobre terrenos de común repartimiento; AHMH/ Tierras/vol. II/ año 1875/ caja $88 /$ exp. 4.

22 Emilio Kourí (2013) menciona que, en la región de Papantla, Veracruz, la desamortización se dio con relativa rapidez debido al incremento de diversos productos en el mercado como la vainilla y la madera. De esta forma, las fértiles tierras de Papantla se tornaron valiosas, lo cual aceleró la individualización de los condueñazgos; aunado a ello, en Papantla los comerciantes lograron dominar el ayuntamiento, por lo cual la desamortización fue favorecida (pp. 197-232, 233-272). Por su parte, Édgar Mendoza afirma que en Cuicatlán, Oaxaca, la introducción del ferrocarril y el impulso de la agricultura comercial de café, tabaco y azúcar originaron el cambio de régimen de propiedad, de corporativa a "privada”. Las tierras comunales (ejidos) más fértiles con acceso al ferrocarril fueron rápidamente desamortizadas y acaparadas por extranjeros, en tanto que las tierras de común repartimiento "privatizadas" fueron conservadas por los indígenas (Mendoza, 2005, pp. 218-226; Mendoza, 2007, pp. 111-127).

23 AHNEM/ Notaría 1/ Fermín Miranda/ 1879/ caja 9/ volumen 5/ fs. 27v-29f.

24 AHNEM/ Notaría 1/ Manuel Artola/ 1889/ caja 11/ protocolo 1/ fs. 9f-11v.

25 AHNEM/ Notaría 1/ Manuel Artola/ 1889/ caja 11/ protocolo 1/ fs. 12f-15f.

26 AHNEM/ Notaría 1/ Remigio Téllez/ 1890/ caja 12/ protocolo 1/ fs. 94f-95v.

27 AHNEM/ Notaría 1/ Antonio Rebollar, Gómez y Pérez/ 1856/ caja 4/ leg. 2/ fs. 209f-211v.

28 AHNEM/ Notaría 1/ Antonio Rebollar, Gómez y Pérez/ 1856/ caja 4/ leg. 2/ fs. 491v-495f.

29 AHNEM/ Notaría 1/ Cayetano Gómez y Pérez/ 1857/ caja 5/leg. 7/ fs. 65v-70f.

30 AHNEM/ Notaría 1/ Cayetano Gómez y Pérez/ 1857/ caja 5/ leg. 8/ fs. 80v-87.

31 AHNEM/ Notaría 1/ Justino Alvarado/ 1887/ caja 11/ leg. 2/ fs. 13f-17v.

32 AHNEM/ Notaría 1/ Zacarías Velázquez/ 1897/ caja 16/ protocolo 8/ fs 6v-9v.

33 AGA/ Cuautitlán/ San Mateo Ixtacalco/ Dotaciones ejidales/ exp. 23-2313/ p. 237.

34 Cuando el pueblo de Santa Bárbara pidió su dotación ejidal en 1916 el Racho del Peral tenía 312 hectáreas y el de Puente Grande 237. Las tierras del primero eran todas de riego, en tanto que el segundo tenía 149 tierras de riego. Del rancho el Peral no hay datos sobre cuántas vacas tenía, pero lo más probable es que también se dedicara a esta actividad. AGA/ Cuautitlán/ Santa Bárbara/ Dotaciones ejidales/ exp. 23-2271 (725.2)/ leg. 1.

35 En 1916 el rancho de Puente Grande tenía 300 vacas lecheras, lo que hace evidente la producción de leche. AGA/ Cuautitlán/ Santa Bárbara/ Dotaciones ejidales/ exp. 23-2271 (725.2)/ leg. 1.

36 AGA/ Cuautitlán/ Santa Bárbara/ Dotaciones ejidales/ exp. 23-2271 (725.2)/ leg. 1. 